\title{
Mixed logit approach to modeling arrival time choice behavior of cemetery and columbarium visitors during grave-sweeping festivals
}

\author{
W.Y. Szeto*, R.C.P. Wong, Jonathan Yeung, S.C. Wong \\ Department of Civil Engineering, The University of Hong Kong, Hong Kong \\ *Corresponding Author, E-mail: ceszeto@hku.hk \\ Phone: (852) 28578552 \\ Fax: (852) 25595337
}

\begin{abstract}
Special events attract extraordinarily high travel demands over a relatively short time. Managing the travel demand for special events is more difficult than for normal commuting trips. Grave-sweeping is a special event that is popular in Asia, especially in Chinese societies. In Hong Kong, many people visit cemeteries and columbaria around the two traditional festivals, causing overcrowding at the sites and congestion on the access roads. To mitigate the adverse traffic effects, the police usually implement temporary traffic management measures to control the number of visitors accessing the sites. However, these measures often ignore visitors' arrival time preferences and hence their effectiveness is questionable. This study models and analyzes the arrival time preferences of cemetery and columbarium visitors under various transport mode scenarios. The model development is based on 3,128 choice decisions collected from 782 respondents. A mixed logit model is calibrated to investigate the potential taste heterogeneity of the respondents, and a likelihood ratio test demonstrates that the model is superior to a standard multinomial logit model and provides a better fit to the survey data. The model results indicate that in-vehicle travel time, total waiting and walking time, and the provision and travel fare of feeder services are significant factors influencing cemetery and columbarium visitors' arrival time choices. The effects of socio-economic factors are also examined and discussed. Based on the model results, recommendations are provided for managing the travel demand to cemeteries and columbaria at peak and off-peak hours on or around festival days.
\end{abstract}

Keywords: cemetery and columbarium trips, arrival time choice, mixed logit model, demand management measures

\section{Introduction}

Traffic congestion is a common phenomenon in many urban cities during rush hours. A well-accepted approach to mitigate such problem is to manage travel demand. The effects of demand management measures on commuting trips have been investigated in numerous studies (e.g., Meyer 1999; Jou et al. 2011; Rotaris and Danielis 2014; Zhang et al. 2014). However, the effects on local traffic induced by special events (e.g., exhibitions, concerts, football matches, and carnivals) are sometimes more severe because special events attract extraordinarily high travel demands within a relatively short period of time. As the travel behavior of special event participants is quite different from that of commuters, it is important to study such behavior so that effective demand management measures can be designed and their effectiveness can be evaluated. 
Grave-sweeping is a popular special event in Asia, especially in Chinese societies (e.g., Hong Kong). During the two grave-sweeping festivals (i.e., Ching Ming Festival and Chung Yeung Festival, on March 6 and September 9 in the lunar calendar, normally held in April and October, respectively), families visit the cemeteries and columbaria where the remains of their ancestors are buried to express filial piety. Many visitors arrive at the cemeteries and columbaria at the same time, causing overcrowding at the sites and congestion on the access roads. At some congested sites, up to 5,000 visitors an hour walk back and forth along walkways less than 10 meters wide. The high demand exceeds the capacity of the access roads and creates a poor walking environment for visitors.

Most of the cemeteries and columbaria in Hong Kong are located in remote areas, some of them on hillsides. It is better to provide feeder services for transporting visitors to and from nearby railway stations or public transport interchanges. Because there are high travel demands to these sites from two weeks before until two weeks after the festival days, more frequent feeder services are provided to improve the service quality. To control the number of visitors accessing some congested sites during peak periods, the police usually implement temporary traffic management measures that prohibit the access of private cars and taxis to congested areas to enhance the feeder services. However, on festival days, when many more visitors attend the sites for gravesweeping, the feeder services are suspended and pedestrian schemes are implemented to ensure adequate walking space for visitors arriving on foot. Sometimes vehicular access is prohibited and feeder services are suspended without prior notice, subject to the onsite judgments of the police (Transport Department 2013a, b). Given the ad-hoc traffic management decisions, travel demand and the crowds cannot be managed effectively as cemetery and columbarium visitors do not receive sufficient information to adjust their travel plans before making the grave-sweeping trips.

All of these temporary traffic management measures are designed without any empirical support and fail to consider visitors' travel behavior. These measures often prolong walking times and cause dissatisfaction among visitors, especially the elderly and people with disabilities. The scale and duration of such measures are often criticized by visitors, and their effectiveness is questionable. Thus, it is important to conduct research to inform the design of appropriate and effective demand management measures to control the crowds.

This study examined the travel behavior of cemetery and columbarium visitors and their arrival time choices given various transport mode scenarios. Many studies have modeled time- and mode-related choices to reveal travelers' trip patterns (e.g., Hunt and Patterson 1996; Bajwa et al. 2008; Ben-Akiva and Abou-Zeid 2013; Habib 2013; Forsey et al. 2014; Siu and Lo 2014; Long et al. 2015). Discrete choice models have been developed for such purposes using field data. This study, conducted in October 2013, involved a headcount survey to measure the number of visitors arriving at two selected cemeteries and columbaria using different transport modes, and a questionnaire interview survey of 782 visitors. We collected data from the respondents regarding their actual arrival time and preferred arrival time under hypothetical scenarios for model calibration. The mixed-preference data collection approach (e.g., Morikawa et al. 1991; Earnhart 2002; Espino 2007; Börjesson 2008; Wen 2010) is wellestablished and avoids the limitations of applying the revealed and stated preference methods independently. In this study, the mixed-preference data collection approach helped to determine visitors' preferences according to their actual chosen arrival time, and thus improve the prediction consequences of a variety of proposed policy measures. Based on the collected data, we developed a standard multinomial logit model to 
investigate how the settings of feeder services and socio-economic factors influenced the visitors' travel decisions. A mixed logit model (also referred to as a random parameter logit model) was also developed to investigate the potential taste heterogeneity of the visitors. The mixed logit modeling approach (e.g., Gkritza and Mannering 2008; Moore et al. 2011; Haleem and Gan 2013; Shaheed et al. 2013) has been widely used to allow the parameter values to vary with taste heterogeneity across observations, and to resolve the problem of the independence of irrelevant alternatives in the standard multinomial logit model (Washington et al. 2011). Following Bliemer and Rose (2013), the coefficients of the time and cost variables were fixed to avoid unfavorable or extreme values in the value-of-time estimation. A likelihood ratio test was carried out to select the best model structure. The discrete choice models determined the significant factors that influenced the visitors' travel decisions. Recommendations on public transport feeder services and the demand management measures are provided to encourage more visitors to arrive at their destination during off-peak periods and hence improve overall visitor satisfaction.

This paper makes several contributions: (1) it proposes discrete choice models that depict the arrival time preferences of cemetery and columbarium visitors during grave-sweeping festivals, (2) it compares the performance of the standard multinomial logit model and the mixed logit model for the studied problem, (3) it identifies the significant factors that influence visitors' travel decisions, and (4) it provides recommendations for diverting peak period travel demand. The findings can serve as a valuable reference for formulating appropriate and effective measures to manage the travel demand and prevent overcrowding at existing cemeteries and columbaria and those to be built in the near future.

The remainder of this paper proceeds as follows. Section 2 provides a brief review of special event studies. Section 3 describes the data collection method, the demographic distribution and travel preferences of the interviewees, the headcount survey, and the options for arrival time and associated transport mode. Section 4 presents the formulations of the standard multinomial logit model and the mixed logit model, and the methodology for comparing their performance. Section 5 discusses the model results and recommends directions for improving the current temporary traffic management measures to control travel demand during peak hours. Section 6 concludes the paper and recommends a future research direction.

\section{Literature Review}

Numerous studies have studied the arrangement of special events and their corresponding demand management measures, focusing on various aspects including modeling travel demand, predicting transport mode choice, modeling pedestrian movements inside and around event venues, and temporary traffic management measures for prohibiting vehicular access. Li et al. (2008) and Kuppam et al. (2013) modeled the travel demands associated with special events held in Beijing and Phoenix City, respectively. In addition to modeling the travel demand, Wong and Yu (2011) investigated the origin-destination pattern of trips to and from a special event held in Macau. Chang and Lu (2013), Shahin et al. (2014), and Pereira et al. (2015) investigated participants' choice of transport mode to various special events. Duives et al. (2013) introduced crowd motion simulation models for high-density crowd movements. Temporary traffic management plans were implemented in response to crowds and high travel demand. Several studies have evaluated temporary traffic management measures 
for special events. In particular, Lassacher et al. (2009) evaluated the temporary traffic management measures in response to the congestion induced by football games in Bozeman City. Consoli et al. (2013) presented a smart event traffic management technique designed for special events held at the Amyway Center in Orlando City. Numerous studies are related to manage the demand associated with various types of special events. However, to the best of the authors' knowledge, few studies have examined the travel behavior of visitors to grave-sweeping festivals and the associated demand management measures for controlling crowds during these festivals. One exception is Szeto et al. (2015), who modeled the travel demand of grave-sweeping visitors in terms of trip attraction, trip distribution, and mode choice. Unlike other special events such as concerts or football matches that have a fixed visiting date and time, visitors to cemeteries and columbaria can choose their preferred date and time to visit around the festival dates (normally from two weeks before until two weeks after the festivals). Thus, the demand management measures suggested for other special events in previous studies cannot be applied directly to the case of grave-sweeping.

\section{Data}

\subsection{Data collection}

A headcount survey and a questionnaire survey were conducted to achieve the research objectives of modeling visitors' preferred arrival time with the respective transport modes to cemeteries and columbaria, and thus improving the current temporary traffic management measures and provision of feeder services. The study was conducted in Chai Wan Chinese Permanent Cemetery and Tseung Kwan O Chinese Permanent Cemetery (both survey venues comprise cemeteries and columbaria). These are two of the largest cemeteries in Hong Kong, and attract many visitors around each festival. Feeder services are provided to transport visitors to and from nearby railway stations. Temporary traffic management measures were implemented on the survey dates to control vehicular access and pedestrian flow to these sites. To ensure adequate walking space for visitors arriving on foot on the peak dates, the feeder services were suspended during certain time periods at both survey venues. The survey was conducted in October 2013, two weeks before and after the Chung Yeung Festival (13 October) from 9 am to $3 \mathrm{pm}$ (categorized into three arrival time periods, 9 to $11 \mathrm{am}, 11$ am to $1 \mathrm{pm}$, and 1 to 3 $\mathrm{pm})$ to measure the number of visitors and interview the visitors on sites. The survey time selection and categorization were based on the findings of the study by Szeto et al. (2015), which modeled the trip attraction, trip distribution, and mode choice of gravesweeping visitors. In their study, a headcount survey was conducted at Chai Wan Cemetery for 4 days during Ching Ming Festival in April 2013 to formulate a daily visitors' arrival profile. They found that the highest number of visitors arrived from 11 am to $1 \mathrm{pm}$ (43.5\% on average, identified as the peak period), and the lowest number arrived from 9 to $11 \mathrm{am}(33.1 \%)$ and 1 to $3 \mathrm{pm}(23.4 \%)$.

In addition to counting the number of arrival visitors only as done in their study, in this study, we further recorded their arrival transport modes, whether on foot or by feeder services, at all of the entrances of the two survey venues. We randomly chose visitors to interview as they entered the sites during the questionnaire survey period. If they did not have sufficient time to complete the questionnaire during the face-to-face interview, we gave them an envelope to return the completed questionnaire to us by mail. Of the 782 completed questionnaires, about three quarters were collected during 
the face-to-face interviews on site and the rest were received by mail. The overall response rate was about 20\%. A sample of questionnaire script is provided in the Appendix. The survey only considered the trip leg between the gathering point and the cemetery because this leg between the gathering point and the cemetery contributes has the most severe effects on local road congestion and overcrowding during or around the festival period, and hence it has to be controlled by temporary traffic management measures at these times. Other trip legs are mainly supported by mass transit railway with high capacity and do not result in congestion and overcrowding.

\subsection{Headcount survey}

Figure 1 shows visitors' arrival time period and transport modes obtained from the headcount survey conducted during three time periods. The headcount distributions of the two sites peaked on the date of the Chung Yeung Festival (13 October) between 11 am and $1 \mathrm{pm}$. Most of the visitors to Chai Wan Cemetery arrived on foot while most of the visitors to Tseung Kwan O Cemetery used the feeder services. It can be explained that the walking time from the nearest railway station to Chai Wan Cemetery s about 17 min, whereas Tseung Kwan O Cemetery was is less convenient, with an estimated walking time of about 24 min from the nearest railway station. Thus, visitors to Tseung Kwan O Cemetery generally prefer the feeder services, leading to a higher travel demand.

Most importantly, we noticed that the travel demand was not spread evenly across the three time periods. If policy measures were implemented to divert the peak period travel demand, the total waiting and walking time of visitors reaching the sites during the peak hours would be shortened and the feeder service quality would be enhanced. 


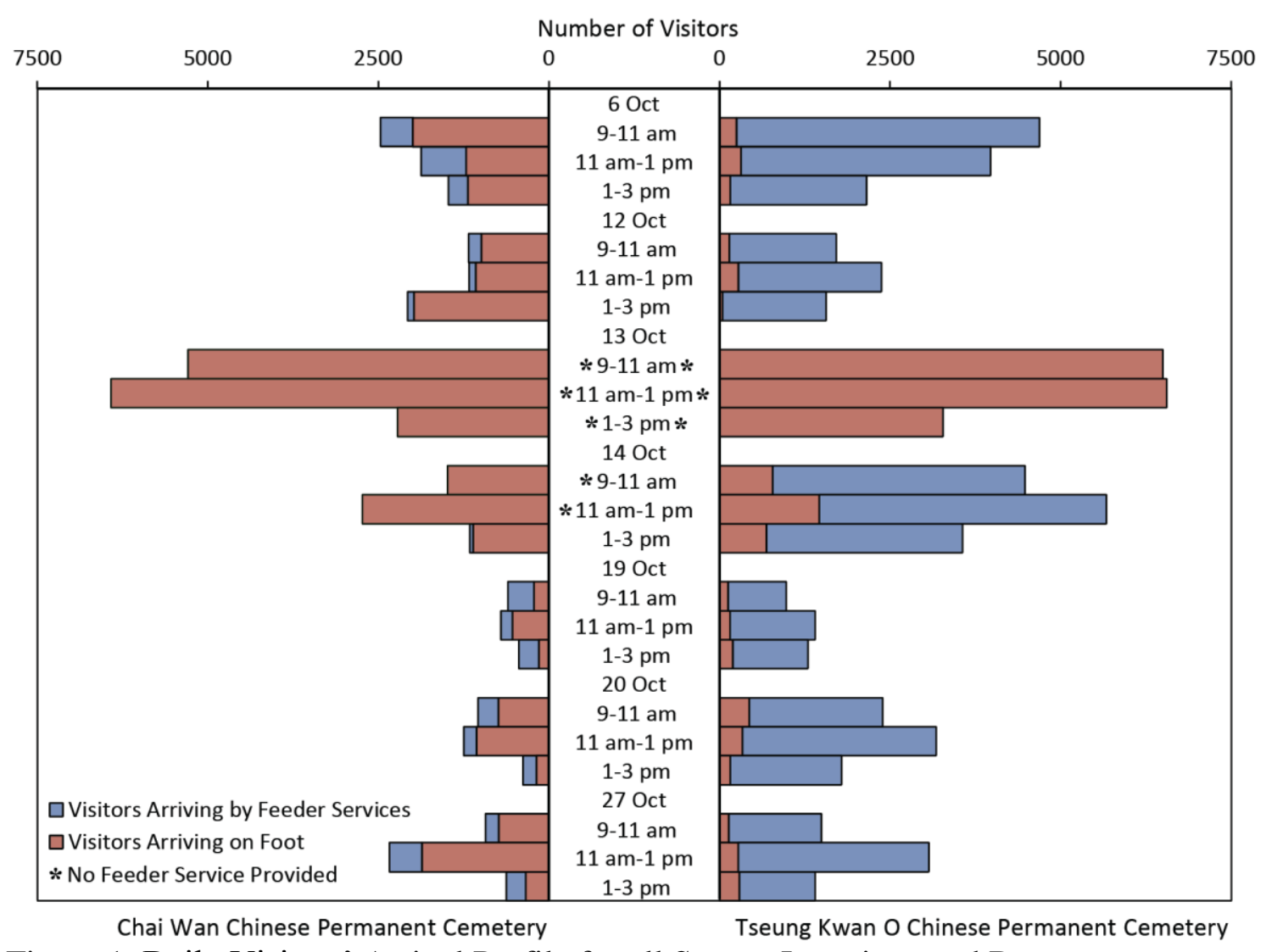

Figure 1. Daily Visitors' Arrival Profile for all Survey Locations and Dates

\subsection{Demographic characteristics of interviewed visitors' families and their preferences for arrival time period and transport mode}

The first section of the questionnaire included background and general questions on visitors' demographic characteristics and their preferences for travelling to the cemeteries and columbaria. Because most of the visitors went grave-sweeping with their families, the interviewees' personal particulars might not be able to explain their family decisions regarding the arrival time period and associated transport mode choices. Thus, we invited the visitors to report their family characteristics including family car ownership, family monthly income, the number of accompanying relatives living apart, and the number of accompanying elderly family members (aged 65 or above), instead of reporting their own personal details such as age, gender, and education level. Their visiting location, date, time period, and transport mode were recorded for model development at a later stage. The visitors were also asked to give reasons for their decisions on the arrival time period and associated transport mode. The visitors' demographic distribution and arrival characteristics are shown in Figure 2. 


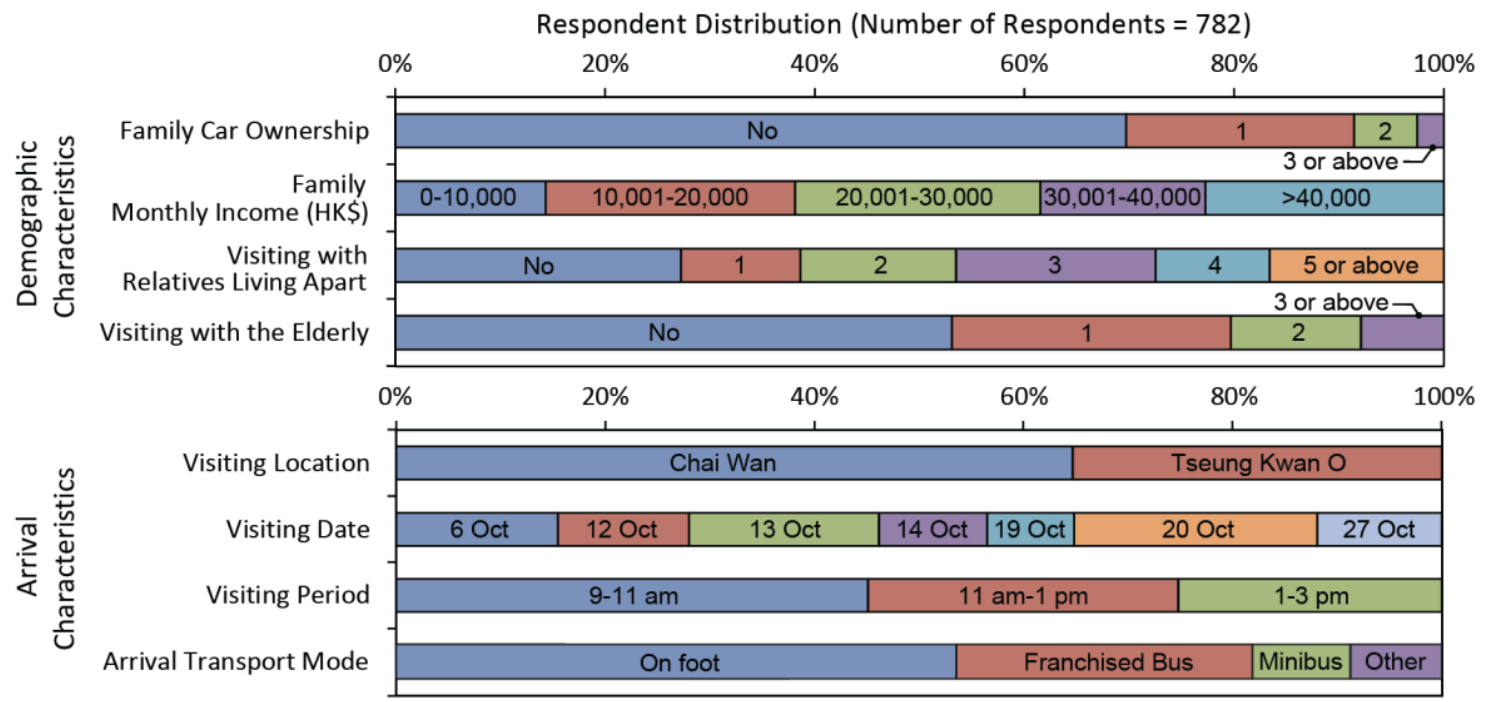

Figure 2. Demographic Characteristics of Interviewed Visitors' Families and their Preferences for Arrival Time Period and Transport Mode

As shown in the upper part of Figure 2, the families of the majority of respondents $(70 \%)$ did not own a private car. As private car access to these two sites was suspended during the survey period, families with a private car may have preferred to visit outside this period for better accessibility. We categorized family monthly income levels into five groups. About $62 \%$ of the interviewed visitors reported that their family income was less than $\mathrm{HK} \$ 30,000$ per month, which is similar to the percentage without access to a car. More than $70 \%$ of visitors were accompanied by relatives living apart. It is likely that these visitors were more resistant to changing their arrival time period because they had to consider the availability of other relatives when deciding when to travel. Furthermore, about $47 \%$ of the visitors reached the sites with at least one elderly family member aged 65 or above. These visitors probably chose to arrive when feeder services were available to avoid a long walk.

The lower part of Figure 2 illustrates the arrival characteristics of the visitors. In general, the samples were evenly distributed across different locations, dates, and time periods. About 54\% of the interviewed visitors reached the sites on foot, while $37 \%$ took the feeder services (including the franchised bus and minibus services) and the rest arrived by other means, such as taxis. Although the visitors had to walk a long way from the nearest railway stations or public transport interchanges, a few (about $11 \%$ out of 54\%) insisted on walking because of the festival tradition and some considered it a good opportunity for hiking. However, the majority of those who came on foot $(43 \%$ out of 54\%) explained that they did so because of the undesirable temporary traffic management measures and inconvenient feeder services. It can be estimated that improving the current temporary traffic measures could encourage more visitors (up to $89 \%$ ) to use the feeder services instead of walking, and thus improve the satisfaction of visitors, especially the elderly and people with disabilities.

\subsection{Visitors' decisions on the arrival time period and transport mode}

Based on our on-site observations, most of the visitors gathered at a nearby railway station or public transport interchange to meet their relatives and to buy ritual supplies before taking the feeder services or walking to the sites. Thus, we asked the visitors to select their preferred arrival time period (i.e., 9-11 am, $11 \mathrm{am}-1 \mathrm{pm}$, or 1-3 pm) with the 
respective transport mode from the nearest railway station under different hypothetical scenarios, based on three given attributes: the in-vehicle travel time of the feeder service, the total waiting and walking time to access the site (including the time for waiting at the station for the feeder service, waiting at the walkway because of tidal crowd control, walking to the station to access the feeder service, and walking to the cemetery), and the travel fare for the feeder service. For some options, the feeder service was suspended to represent the implementation of pedestrianization schemes (i.e., the in-vehicle travel time was equal to zero). In this case, the travel fare was set to zero and the total waiting and walking times were significantly prolonged. As most of the visitors went gravesweeping with their families, we reminded the respondents to consider the physical condition of their accompanying family members when making their decisions.

Table 1. Attributes and Levels Adopted for the Stated Preference Survey

\begin{tabular}{|l|l|c|}
\hline \multicolumn{1}{|c|}{ Choices } & \multicolumn{1}{|c|}{ Attributes } & Levels \\
\hline \multirow{4}{*}{$\begin{array}{l}\text { Arrival time period (1): } \\
\text { 9-11 am }\end{array}$} & In-vehicle travel time (min) & $0,5,10$ \\
\cline { 2 - 3 } & $\begin{array}{l}\text { Total waiting and walking time } \\
(\mathrm{min})\end{array}$ & $\begin{array}{c}8,12,16 \\
(25,30,35)^{\mathrm{a}}\end{array}$ \\
\cline { 2 - 3 } & Travel fare (HK\$) & $2,5,8(0)^{\mathrm{a}}$ \\
\hline $\begin{array}{l}\text { Arrival time period (2): } \\
\text { 11-1 pm }\end{array}$ & $\begin{array}{l}\text { Total waiting and walking time } \\
(\text { min) }\end{array}$ & $40,45,50$ \\
\hline \multirow{3}{*}{$\begin{array}{l}\text { Arrival time period (3): } \\
1-3 \text { pm }\end{array}$} & In-vehicle travel time (min) & $0,8,12$ \\
\cline { 2 - 3 } & $\begin{array}{l}\text { Total waiting and walking time } \\
(\text { min) }\end{array}$ & $\begin{array}{c}5,10,15 \\
(25,30,35)^{\mathrm{a}}\end{array}$ \\
\cline { 2 - 3 } & Travel fare (HK\$) & $4,7,10(0)^{\mathrm{a}}$ \\
\hline
\end{tabular}

Note: ${ }^{\mathrm{a}}$ The values in parentheses were adopted when no feeder service was available and the in-vehicle travel time equaled zero.

We adopted the fractional factorial design method to generate 27 profiles for our choice experiments, and randomly assigned them to 7 sets of questionnaires (each set of questionnaires contained 4 hypothetical games). Thus, we obtained 3,128 observations from the 782 interviewed visitors. Table 1 shows the attributes and levels adopted in the stated preference survey. The levels of the in-vehicle travel time, the total waiting and walking time, and the travel fare for different options were defined with reference to the past experience of visiting the cemeteries. As Figure 1 shows that the peak period for visiting both cemeteries was between 11 am and $1 \mathrm{pm}$, we considered that the pedestrianization scheme would need to be implemented to cater for the high travel demand during these two hours. Furthermore, providing feeder services during the peak period would attract more visitors and cause more severe overcrowding at the sites and congestion on the access roads, which would not match with our objective to divert travel demand to off-peak periods. Thus, we excluded it as a possible option in our questionnaire.

\section{Methodology}

\subsection{Multinomial logit model}

To determine the significant factors that affect visitors' choice of arrival time period with the given scenarios of transport mode provision, we adopted the standard 
multinomial logit modeling approach at first based on the stated preference questionnaire survey data. The model takes the following form (McFadden 1974):

$$
P_{q}(j)=\frac{\exp \left[U_{q}(j)\right]}{\sum_{m \in J} \exp \left[U_{q}(m)\right]},
$$

where $P_{q}(j)$ is the probability that a visitor $q$ selects arrival time period $j$ and the respective transport mode to reach his/her designated cemetery for grave-sweeping. $J$ is the set of alternatives considered. $U_{q}(j)$ is the deterministic utility associated with period $j$ which captures the factors influencing the travel decision of visitor $q$, and is mathematically expressed as:

$$
U_{q}(j)=\beta^{\mathrm{T}} T_{j}+\beta^{\mathrm{W}} W_{j}+\beta^{\mathrm{F}} F_{j}+\beta^{\mathrm{S}} S_{j}+C_{j q}\left(\beta^{\mathrm{I}} I_{q}+\beta^{\mathrm{R}} R_{q}+\beta^{\mathrm{E}} E_{q}\right),
$$

where $T_{j}, W_{j}$, and $F_{j}$ denote the in-vehicle travel time, the total waiting and walking time, and the travel fare for the feeder service of the given transport mode in alternative arrival time period $j$, respectively. $S_{j}$ is an additional binary variable introduced in Equation (2) to represent the effect of feeder service provision on visitors' travel decisions; it equals one if feeder services are available in arrival time period $j$, and otherwise zero. $\beta^{\mathrm{T}}, \beta^{\mathrm{W}}, \beta^{\mathrm{F}}$, and $\beta^{\mathrm{S}}$ are the coefficients corresponding to $T_{j}, W_{j}$, $F_{j}$, and $S_{j} \cdot C_{j q}\left(\beta^{\mathrm{I}} I_{q}+\beta^{\mathrm{R}} R_{q}+\beta^{\mathrm{E}} E_{q}\right)$ is a constant in the utility function of the actual arrival time period chosen by visitors (recorded during the questionnaire survey). It is introduced to reflect visitors' insistence on following their original plan to reach their destination during their desired arrival time period. $C_{j q}$ is a binary variable to indicate whether the selected arrival time period $j$ in the hypothetical scenario is the same as the actual arrival time period chosen by visitor $q$; it equals one if the two periods are the same and zero otherwise. We assumed that visitors with different socioeconomic characteristics may differ in their level of insistence when choosing arrival time periods. Thus, we incorporated the family characteristics $I_{q}, R_{q}$, and $E_{q}$ (i.e., family monthly income, visited with relatives living apart, and visited with elderly family members) into the model. Specifically, $I_{q}$ equals one if the family monthly income of visitor $q$ was higher than $\mathrm{HK} \$ 30,000$ and zero otherwise; $R_{q}$ equals one if visitor $q$ was accompanied by relatives living apart and zero otherwise; and $E_{q}$ equals one if visitor $q$ was accompanied by elderly family members and zero otherwise. $\beta^{\mathrm{I}}$, $\beta^{\mathrm{R}}$, and $\beta^{\mathrm{E}}$ are the coefficients corresponding to $I_{q}, R_{q}$ and $E_{q}$, respectively.

Note that to generate statistically significant results, we grouped the arrival times into three time periods (i.e., 9 to $11 \mathrm{am}, 11 \mathrm{am}$ to $1 \mathrm{pm}$, and 1 to $3 \mathrm{pm}$ ) instead of modeling arrival time as a continuous variable or using other number of arrival time periods. Moreover, application of the model for planning temporary traffic management measures may not require precise predictions of each visitor's arrival time, modeling the 
arrival time period is sufficient to achieve our research objective and for real-world applications.

\subsection{Mixed logit model}

In addition to the above multinomial logit model, we developed a mixed logit (random parameter logit) model to capture the unobserved heterogeneity across the respondents. The mixed logit model takes the following form (McFadden and Train 2000):

$$
P_{q}(j \mid \phi)=\int \frac{\exp \left[U_{q}(j)\right]}{\sum_{m \in J} \exp \left[U_{q}(m)\right]} f(\beta \mid \phi) d \beta,
$$

where $\beta$ is a vector of coefficients, $\phi$ is a vector of the parameters (e.g., mean and variance for a normal distribution) of the density function used, and $f(\beta \mid \phi)$ is the density function of $\beta$ given $\phi$. The $\beta$ distribution may allow for individual-level variations in the effects of the attributes. The distribution is flexible in the sense that $\beta$ may be fixed and when all parameters are fixed, the model reduces to the standard multinomial logit formulation. In instances where $\beta$ is allowed to vary, the model is open form and the probability of visitor $q$ choosing arrival time period $j$ with the respective transport mode may be calculated through integration. The random parameters are predetermined under the normal distribution. This modeling approach is widely used and has been shown to be superior to the uniform, log-normal, and triangular distributions (Haleem and Gan 2013).

\subsection{Likelihood ratio test for model comparison}

To test whether the standard multinomial logit model or the mixed logit model provides the best structure for modeling the arrival time choice behavior of cemetery and columbarium visitors, the likelihood ratio test, also referred to as the Watson and Westin pooling test (Watson and Westin 1975), was applied to compare the goodness of fit of the models. The test is based on the log-likelihood ratio (LR):

$$
\mathrm{LR}=-2\left(L_{\mathrm{R}}-L_{\mathrm{U}}\right)
$$

where $L_{R}$ is the log-likelihood of the restricted multinomial logit model, and $L_{U}$ is the log likelihood of the unrestricted mixed logit model. The null hypothesis that the two model structures are equally good is rejected if the test statistic exceeds the critical value specified by the chi-square distribution at the chosen level of significance. The degree of freedom is the difference between the number of variables in the two models.

\section{Model results and discussion}

\subsection{Results of multinomial logit model and mixed logit model}


An econometric modeling software NLOGIT was adopted to determine the coefficient of each variable in the standard multinomial logit model and the mixed logit model. The coefficient of each variable in the models is given in Table 2.

Table 2. Results of Multinomial Logit Model and Mixed Logit Model

\begin{tabular}{|c|c|c|c|}
\hline \multirow{2}{*}{\multicolumn{2}{|c|}{ Explanatory variables }} & \multicolumn{2}{|c|}{ Coefficients [t-statistics] $^{\mathrm{a}}$} \\
\hline & & $\begin{array}{l}\text { Multinomial } \\
\text { logit model }\end{array}$ & $\begin{array}{l}\text { Mixed logit } \\
\text { model }\end{array}$ \\
\hline \multicolumn{2}{|c|}{ In-vehicle travel time (min) } & $-0.10^{\mathrm{b}}[-7.4]$ & $-0.14^{b}[-8.4]$ \\
\hline \multicolumn{2}{|c|}{ Total waiting and walking time (min) } & $-0.05^{\mathrm{b}}[-12.0]$ & $-0.07^{\mathrm{b}}[-10.3]$ \\
\hline \multicolumn{2}{|c|}{ Travel fare (HK\$) } & $-0.14^{\mathrm{b}}[-10.0]$ & $-0.18^{b}[-12.4]$ \\
\hline \multicolumn{2}{|c|}{ Feeder service provision } & $1.51^{b}[9.5]$ & $1.90^{b}[9.5]$ \\
\hline \multicolumn{2}{|c|}{$\begin{array}{l}\text { Standard deviation associated with feeder service } \\
\text { provision }\end{array}$} & -- & $1.93^{\mathrm{b}}[9.2]$ \\
\hline \multirow{3}{*}{$\begin{array}{l}\text { Chosen arrival } \\
\text { time period }\end{array}$} & High family monthly income & $0.17^{\mathrm{C}}[2.1]$ & $0.23^{\mathrm{c}}[2.3]$ \\
\hline & Visiting with relatives living apart & $0.94^{\mathrm{b}}[13.2]$ & $1.14^{\mathrm{b}}[12.4]$ \\
\hline & Visiting with the elderly & $-0.01[-0.1]$ & $0.01[0.1]$ \\
\hline
\end{tabular}

Note: ${ }^{\mathrm{a}}$ The values in brackets represent the t-statistics of the explanatory variables.

${ }^{\mathrm{b}}$ Parameters are significant at the $1 \%$ level.

${ }^{\mathrm{c}}$ Parameters are significant at the 5\% level.

The first three quantitative attributes in both models have negative coefficients ranging from -0.18 to -0.05 , which are significant at the $1 \%$ level. This implies that the cemetery and columbarium visitors preferred to visit during periods when a given transport mode has a shorter in-vehicle travel time, shorter total waiting and walking time, and a lower travel fare. The results are logical. The binary variable for the feeder service provision is significant at the $1 \%$ level in the two models, and the associated coefficients are 1.51 and 1.90 for the multinomial logit model and the mixed logit model, respectively. This shows that cemetery and columbarium visitors generally preferred to take feeder services instead of walking, which concurs with our preliminary findings discussed in Section 3.2. The value of total waiting and walking time is around HK\$0.4 per minute in both models, which is about half of that of in-vehicle travel time.

In addition to the socio-economic factors, Table 2 shows that only the first two binary variables, representing visitors who had a high family monthly income and visited with relatives living apart, are statistically significant and have a positive coefficient. The results imply that visitors with these socio-economic characteristics had a strong preference for arriving in the same time period that they had actually visited the site. This result suggests that if visitors have to compromise their personal schedule and their relatives' availability, they might prefer a particular arrival time period and give less consideration to the cost and availability of the feeder service. However, the model results show that visiting with an elderly relative is not significant at the 5\% level, which implies that these visitors did not show any preference for a specific arrival time period, but instead looked for a time period when feeder services were provided. Because the walking times to the cemeteries (17 min for Chai Wan Cemetery and 24 min for Tseung Kwan O Cemetery) are too long for the elderly to manage on foot, their choice of arrival time period could be easily influenced by providing feeder services for them.

Specifically for the mixed logit model, only the standard deviation associated with feeder service provision is significant (and the standard deviations associated with other explanatory variables are found to be insignificant), which shows the unobserved 
heterogeneity between visitors regarding feeder service provision. Given that the random coefficient is normally distributed and the standard deviation is 1.93, about $16.3 \%$ of visitors would prefer not to arrive when feeder services are provided. In other words, these visitors prefer a pedestrianization scheme that restricts all vehicular access, reserving the whole route for walking. A pedestrianization scheme would allow much more space for walking, which would be greatly reduced by the provision of feeder services and thus spoil the enjoyment of those visitors who wanted to walk and enjoy the environment. The proportion of visitors with a negative perception of feeder services also concurs with the finding in Section 3.2, that about $11 \%$ of visitors insisted on walking because it is part of the traditional culture and offers a good opportunity for hiking.

\subsection{Results of the likelihood ratio test}

Table 3 shows the log-likelihood values of the two models used to calculate the LR. Given that the degree of freedom is 1 , the corresponding chi-square critical value at the $1 \%$ significance level is 6.6 , which is obviously lower than the calculated log-likelihood ratio of 49.6. Thus, the null hypothesis that the two model structures are equally good is rejected accordingly. Because the mixed logit model gives a higher maximum loglikelihood value than that of the multinomial logit model, the likelihood ratio test result demonstrates that the mixed logit model is superior to the standard multinomial logit model and better fits the survey data.

Table 3. Results of the Likelihood Ratio Test

\begin{tabular}{|c|c|c|}
\hline \multicolumn{2}{|c|}{ Measures / conclusions } & Results \\
\hline \multirow{2}{*}{ Log likelihood } & Multinomial logit model & -2667.2 \\
\hline & Mixed logit model & -2642.4 \\
\hline \multicolumn{2}{|l|}{ LR } & 49.6 \\
\hline \multicolumn{2}{|c|}{ Chi-square critical value $^{\mathrm{a}}$} & 6.6 \\
\hline \multicolumn{2}{|c|}{ Conclusion of the hypothesis test $^{b}$} & Reject \\
\hline
\end{tabular}

Note: ${ }^{a}$ The chi-square critical value when the degree of freedom is 1 and the significance level is 0.01 .

$\mathrm{b}$ The null hypothesis test at the $99 \%$ confidence interval.

\subsection{Recommendations to divert peak period travel demand}

The mixed logit model results show that visitors who had a high family income or visited with relatives living apart preferred to follow their original plan to visit the cemeteries and columbaria for grave-sweeping. Fortunately, the sum of these coefficients (1.37 for the mixed logit model) is not large compared to the other coefficients. From the mixed logit model results shown in Table 2, the binary variable for feeder service provision has a larger coefficient than the other explanatory variables, indicating that the provision of feeder services significantly influenced the choice of arrival time period. Providing frequent feeder services with a low travel fare during offpeak periods only (i.e., 9-11 am and 1-3 pm) could shift a proportion of visitors who would normally visit during the peak period (i.e., $11 \mathrm{am}-1 \mathrm{pm}$ ) to the off-peak periods. This would achieve the objective of diverting peak period travel demand to off-peak periods. These measures should be particularly attractive to visitors who are accompanied by elderly family members. Given that about half of the visitors travelled 
with elderly relatives, as illustrated in Figure 2, providing feeder services could be an effective policy measures to divert the peak period travel demand. According to the headcount survey results, the travel demand peaked from 11 am to $1 \mathrm{pm}$. We suggest, therefore, that feeder services should be provided only during the off-peak periods rather than the whole day. This could encourage visitors to arrive at the cemeteries or columbaria during off-peak periods and thus achieve a better balance between the capacity of feeder services and travel demand.

The travel demand distribution throughout the day can be further adjusted by modifying the travel fare and frequency (which affects the waiting time) of the feeder services. Based on the results discussed above, a discount on the travel fare (e.g., a 25\% reduction on travel during off-peak periods) would provide an additional incentive for visitors to adjust their arrival times. This incentive would be particularly effective for visitors with lower family monthly incomes. The service quality could be further improved by increasing the service fleet size to reduce the waiting time. Given that these improvement measures may cause profit loss to the feeder service providers, subsidization from the government should be considered. The models can be applied to estimate the outcomes of the potential recommendations and an evaluation of costeffectiveness can then be conducted to determine an appropriate subsidy level.

It is important to point out that data on visitors' actual travel choices should be collected and the policy measures should be reviewed periodically to ensure the proposed policy measures are up-to-date and reflect current demand.

We believe that promotion of the traffic management measures is crucial for them to be effective. Visitors make their decisions according to their best knowledge of the temporary traffic management measures and the feeder service provision on the day of their visit. Failing to inform visitors properly would be of no use despite the good intentions. Currently, the temporary traffic management measures are posted on the website of the Transport Department and announced through radio broadcasting. However, most of the respondents were unclear about the details of the arrangements. Improving communication with the public through the use of electronic channels such as social media would ensure that the information on temporary traffic management measures reached all visitors before starting their trips.

\section{Conclusion}

This study models and analyzes visitors' preferred arrival times at cemetery and columbaria during grave-sweeping festivals. A questionnaire survey was completed by 782 respondents who visited the survey locations, to capture their travel choices under four hypothetical scenarios. In total, 3,128 observations were collected and used to calibrate the discrete choice models for the analysis. A standard multinomial logit model and a mixed logit model were developed and calibrated. The results of the likelihood ratio test showed that the mixed logit model outperformed the multinomial logit model in modeling visitors' choice of arrival time, and was also able to capture the unobserved heterogeneity among the visitors. Both models concurred that the in-vehicle travel time, the total waiting and walking time, and the travel fare were the significant factors influencing visitors' choice of arrival time. The model results also demonstrated that visitors accompanied by elderly family members had no preference for a specific arrival time period, but looked for a time when feeder services were provided. Hence, it should be possible to influence their choice of arrival time period by providing feeder services. The mixed logit model also demonstrated that the standard deviation 
associated with the binary variable for feeder service provision was significant at the $1 \%$ level, indicating the unobserved heterogeneity among visitors regarding feeder service provision. Only $16.3 \%$ of visitors preferred the pedestrianization scheme and the rest preferred to use feeder services.

Based on the model results, we suggest (1) providing feeder services during offpeak periods (i.e., 9-11 am and 1-3 pm) only, to shift some of the peak-period visitors, especially those visiting with elderly family members, to the off-peak periods; and (2) adjusting the travel fare and frequency of feeder services to provide an additional incentive for visitors to change their arrival time periods especially those with a lower family monthly income. Given that these improvement measures may cause profit loss to the feeder service providers, subsidization from the government should be considered. The models can be applied to estimate the outcomes of the potential recommendations and an evaluation of cost-effectiveness can then be conducted to determine an appropriate subsidy level. We believe that our findings can serve as a valuable reference for formulating appropriate and effective demand management measures to manage the crowds travelling to cemeteries and columbaria around the festivals. However, the findings of the proposed models cannot be used to suggest the optimal setting of service provision of feeder services for cemetery and columbarium trips to achieve either consumer surplus maximization to the public or profit maximization to the service providers. A further study is thus recommended for an optimal solution.

\section{Acknowledgements}

This research was supported by a grant from the Research Grants Council of the Hong Kong Special Administrative Region, China (HKU7026-PPR-12). The authors wish to thank Winky Wing Ki LAM, a student of the Civil Engineering Department, The University of Hong Kong, for her assistance with the data collection and analysis. The authors are also grateful to the constructive comments from the three reviewers and the Editor-in-chief, Prof. William H.K. Lam.

\section{References}

Bajwa, S., S. Bekhor, M. Kuwahara, and E. Chung. 2008. "Discrete Choice Modeling of Combined Mode and Departure Time." Transportmetrica 4 (2): 155-177.

Ben-Akiva, M., and M. Abou-Zeid. 2013. "Methodological Issues in Modelling Timeof-Travel Preferences." Transportmetrica A: Transport Science 9 (9): 846-859.

Bliemer, M. C. J., and J. M. Rose. 2013. "Confidence Intervals of Willingness-To-Pay for Random Coefficient Logit Models." Transportation Research Part B: Methodological 58: 199-214.

Börjesson, M. 2008. "Joint RP-SP Data in a Mixed Logit Analysis of Trip Timing Decisions." Transportation Research Part E: Logistics and Transportation Review 44(6) 1025-1038.

Chang, M. S., and P. R. Lu. 2013. "A Multinomial Logit Model of Mode and Arrival Time Choices for Planned Special Events." Journal of the Eastern Asia Society for Transportation Studies 10: 710-727.

Consoli, F., J. Rogers, H. Al-Deek, O. Tatari, and A. Alomari. 2013. "Smart Event Traffic Management: Impact on the Central Florida Regional Transportation Network and Lessons Learned." Transportation Research Record: Journal of the Transportation Research Board 2396: 107-116. 
Duives, D. C., W. Daamen, and S. P. Hoogendoorn. 2013. "State-of-the-Art Crowd Motion Simulation Models." Transportation Research Part C: Emerging Technologies 37: 193-209.

Earnhart, D., 2002. "Combining Revealed and Stated Data to Examine Housing Decisions Using Discrete Choice Analysis." Journal of Urban Economics 51 (1): 143-169.

Espino, R., J. de D. Ortúzar, and C. Román, C. 2007. "Understanding Suburban Travel Demand: Flexible Modeling with Revealed and Stated Choice Data." Transportation Research Part A: Policy and Practice 41 (10): 899-912.

Forsey, D., K. N. Habib, E. J. Miller, and A. Shalaby. 2014. "Temporal Transferability of Work Trip Mode Choice Models in an Expanding Suburban Area: the Case of York Region, Ontario.” Transportmetrica A: Transport Science 10 (6): 469482.

Gkritza, K., and F. Mannering. 2008. "Mixed Logit Analysis of Safety-Belt Use in Single- And Multi-Occupant Vehicles." Accident Analysis and Prevention 40 (2): 443-451.

Habib, K. M. N. 2013. “A Joint Discrete-Continuous Model Considering Budget Constraint for the Continuous Part: Application in Joint Mode and Departure Time Choice Modelling." Transportmetrica A: Transport Science 9 (2): 149177.

Haleem, K., and A. Gan. 2013. "Effect of Driver's Age and Side of Impact on Crash Severity Along Urban Freeways: A Mixed Logit Approach.” Journal of Safety Research 46: 67-76.

Hunt, J. D., and D. M. Patterson. 1996. "A Stated Preference Examination of Time of Travel Choice for a Recreational Trip." Journal of Advanced Transportation 30 (3): $17-44$.

Jou, R. C., C. C. Chen, and Y. L. Chen. 2011. "The Effects of Travellers' Acceptance/Satisfaction of Unimplemented/Implemented Transportation Demand Management Strategies on Travel Behaviour." Transportmetrica 7 (3): 201-228.

Kuppam, A., R. Copperman, J. Lemp, T. Rossi, V. Livshits, L. Vallabhaneni, K. Jeon, and E. Brown. 2013. "Special Events Travel Surveys and Model Development." Transportation Letters 5 (2): 67-82.

Lassacher, S., D. Veneziano, S. Albert, and Z. Ye. 2009. "Traffic Management of Special Events in Small Communities." Transportation Research Record: Journal of the Transportation Research Board 2099: 85-93.

Li, C. Y., J. C. Chen, J. F. Guo, and X. K. Yang. 2008. "Exploration of Demand Model for 2008 Olympic Games in Beijing." Transportation Research Board 87th Annual Meeting, Washington DC, United States.

Long, J., W. Y. Szeto, Q. Shi, Z. Gao, and H. J. Huang. 2015. “A Nonlinear Equation System Approach to the Dynamic Stochastic User Equilibrium Simultaneous Route and Departure Time Choice Problem." Transportmetrica A: Transport Science 11 (5): 388-419.

McFadden, D. 1974. "Conditional Logit Analysis of Qualitative Choice Behavior." In Frontiers in Econometrics, edited by P. Zarembka, 105-142. New York: Academic Press.

McFadden, D., and K. Train. 2000. "Mixed MNL Models for Discrete Response." Journal of Applied Econometrics 15: 447-470.

Meyer, M. D. 1999. "Demand Management as an Element of Transportation Policy: Using Carrots and Sticks to Influence Travel Behavior." Transportation 
Research Part A: Policy and Practice 33 (7-8): 575-599.

Moore, D. N., W. H. Schneider IV, P. T. Savolainen, and M. Farzaneh. 2011. "Mixed Logit Analysis of Bicyclist Injury Severity Resulting from Motor Vehicle Crashes at Intersection and Non-Intersection Locations." Accident Analysis and Prevention 43 (3): 621-630.

Morikawa, T., M. Ben-Akiva, and K. Yamada. 1991. "Forecasting Intercity Rail Ridership Using Revealed Preference and Stated Preference Data." Transportation Research Record: Journal of the Transportation Research Board, 1328, 30-35.

Pereira, F. C., F. Rodrigues, and M. Ben-Akiva. 2015. "Using Data from the Web to Predict Public Transport Arrivals under Special Events Scenarios." Journal of Intelligent Transportation Systems 19(3): 273-288.

Rotaris, L., and R. Danielis. 2014. "The Impact of Transportation Demand Management Policies on Commuting to College Facilities: A Case Study at The University of Trieste, Italy." Transportation Research Part A: Policy and Practice 67: 127140.

Shaheed, M. S. B., K. Gkritza, W. Zhang, and Z. Hans. 2013. "A Mixed Logit Analysis of Two-Vehicle Crash Severities Involving a Motorcycle." Accident Analysis and Prevention 61: 119-128.

Shahin, S., T. O. Hüseyin, and Ö. S. Kemal. 2014. "Evaluating Transportation Preferences for Special Events: A Case Study for a Megacity, Istanbul." Procedia - Social and Behavioral Sciences 111: 98-106.

Siu, B. W. Y., and H. K. Lo. 2014. "Punctuality-based Route and Departure Time Choice." Transportmetrica A: Transport Science 10 (7): 585-621.

Szeto, W. Y., J. Yeung, R. C. P. Wong, and W. H. Yang. 2015. "Trip Attraction, Trip Distribution, and Modal Split for Columbarium Trips." Journal of the Eastern Asia Society for Transportation Studies, in press.

Transport Department. 2013a. Special Traffic and Transport Arrangements in Chai Wan for Chung Yeung Festival 2013, Transport Department Notice. Hong Kong SAR Government.

Transport Department. 2013b. Special Traffic and Transport Arrangements on Hong Kong Island for Ching Ming Festival 2013, Transport Department Notice. Hong Kong SAR Government.

Washington, S. P., M. G. Karlaftis, and F. L. Mannering. 2011. Statistical and Econometric Methods for Transportation Data Analysis. Boca Raton: Chapman \& Hall/CRC.

Watson, P. L., and R. B. Westin. 1975. "Transferability of Disaggregate Mode Choice Models." Regional Science and Urban Economics 5 (2): 227-249.

Wen, C. H. 2010. "Alternative Tree Structures for Estimating Nested Logit Models with Mixed Preference Data." Transportmetrica 6 (4): 291-309.

Wong, K. I., and S. A. Yu. 2011. "Estimation of Origin-Destination Matrices for Mass Event: A Case of Macau Grand Prix." Journal of King Saud University-Science 23 (3): 281-292.

Zhang, Z., H. Fujii, and S. Managi. 2014. "How Does Commuting Behavior Change Due to Incentives? An Empirical Study of the Beijing Subway System." Transportation Research Part F: Traffic Psychology and Behaviour 24: 17-26. 


\section{Appendix: Sample of Questionnaire Script}

\section{[Please tick as appropriate]}

Survey venue:

$\square$ Chai Wan Cemetery

Survey date:

$\square 6 \quad \square 12 \quad \square 13$

\section{$\square 14$}

$\square$ Tseung Kwan O Cemetery

Actual arrival time period:

$\square 9-11$ am

$\square 11 \mathrm{am}-1 \mathrm{pm}$

$\square 27$ of October
$\square 1-3 \mathrm{pm}$

\section{A) Travel decisions to the cemetery or columbarium for grave-sweeping}

A1. Reason(s) of arriving at the cemetery or columbarium on the current date and during the current time period for grave-sweeping (allow multiple answers)
$\square$ Avoid visiting with crowd
$\square$ Avoid visiting under high temperature
$\square$ Consider accompanying relatives' schedules
$\square$ Consider other planned activities
$\square$ Consider lunch hour
$\square$ Consider road closure arrangement
$\square$ Consider feeder service provision
$\square$ Convenient for buying ritual supplies
$\square$ Others (please specify:

A2. How did you arrive at the cemetery or columbarium?

$\begin{array}{ll}\square \text { On foot without taking feeder services } & \square \text { By bus } \\ \square \text { By minibus } & \square \text { Others (please specify: }\end{array}$

[Skip this question if not selected "on foot without taking feeder services" in Question A2]

A3. Reason(s) of walking to the cemetery or columbarium (allow multiple answers)
$\square$ Road closure to prohibit vehicular access
$\square$ Fail to find stops for feeder services
$\square$ Traffic congestion on access roads
$\square$ Long waiting time for feeder services
$\square$ Festival tradition
$\square$ Convenient to access on foot
$\square$ High travel fare
$\square$ Others (please specify:

A4. Did you clearly know the details of temporary traffic management measures before you started this journey to the cemetery or columbarium?

$\square$ Yes $\quad \square$ No

A5. Did you satisfy with the implemented temporary traffic management measures?

$\square$ Yes $\quad \square$ No

[Skip this question if not select "no" in Question A5]

A6. Reason(s) of making you dissatisfied with the temporary traffic management measures (allow multiple answers)

$\square$ Unclear or insufficient directional signs

$\square$ Long walking and waiting times

$\square$ Inconvenient to the elderly and disabled visitors

$\square$ Insufficient promotion to the public

$\square$ Long duration of road closure

$\square$ Others (please specify:

\section{B) Arrival time choices to the cemetery or columbarium for grave-sweeping}

Assume that you are planning a trip to the cemetery or columbarium for grave-sweeping during festivals. In the following four independent games, please choose the most preferred option of arrival time period with the respective transport mode to access the site from the nearest railway station in each game (please be reminded to consider the physical conditions of your accompanying family members). 


\begin{tabular}{|l|l|c|}
\hline & $\begin{array}{l}\text { Arrive during } 9 \text { to } 11 \text { am. Walk to the cemetery which takes } 25 \text { minutes for } \\
\text { waiting and walking (prohibited all vehicular access). }\end{array}$ & $\square$ \\
\cline { 2 - 3 } Game 1 & $\begin{array}{l}\text { Arrive during } 11 \text { am to } 1 \mathrm{pm} \text {. Walk to the cemetery which takes } 40 \text { minutes for } \\
\text { waiting and walking (prohibited all vehicular access). }\end{array}$ & $\square$ \\
\cline { 2 - 3 } & $\begin{array}{l}\text { Arrive during } 1 \text { to } 3 \text { pm. Travel to the cemetery by a feeder service which takes } \\
8 \text { minutes for in-vehicle travel and } 5 \text { minutes for waiting and walking, and } \\
\text { requires paying a fare of } \$ 4 .\end{array}$ & $\square$ \\
\hline
\end{tabular}

\begin{tabular}{|l|l|c|}
\hline \multirow{5}{*}{ Game 2} & $\begin{array}{l}\text { Arrive during } 9 \text { to } 11 \text { am. Walk to the cemetery which takes } 30 \text { minutes for } \\
\text { waiting and walking (prohibited all vehicular access). }\end{array}$ & $\square$ \\
\cline { 2 - 3 } & $\begin{array}{l}\text { Arrive during } 11 \text { am to } 1 \text { pm. Walk to the cemetery which takes } 45 \text { minutes for } \\
\text { waiting and walking (prohibited all vehicular access). }\end{array}$ & $\square$ \\
\cline { 2 - 3 } & $\begin{array}{l}\text { Arrive during } 1 \text { to } 3 \text { pm. Travel to the cemetery by a feeder service which takes } \\
12 \text { minutes for in-vehicle travel and } 15 \text { minutes for waiting and walking, and } \\
\text { requires paying a fare of } \$ 10 .\end{array}$ & $\square$ \\
\hline
\end{tabular}

\begin{tabular}{|l|l|l|}
\hline & $\begin{array}{l}\text { Arrive during } 9 \text { to } 11 \text { am. Travel to the cemetery by a feeder service which takes } \\
10 \text { minutes for in-vehicle travel and } 8 \text { minutes for waiting and walking, and } \\
\text { requires paying a fare of } \$ 5 .\end{array}$ & $\square$ \\
\cline { 2 - 4 } Game 3 & $\begin{array}{l}\text { Arrive during } 11 \text { am to } 1 \text { pm. Walk to the cemetery which takes } 50 \text { minutes for } \\
\text { waiting and walking (prohibited all vehicular access). }\end{array}$ & $\square$ \\
\cline { 2 - 3 } & $\begin{array}{l}\text { Arrive during } 1 \text { to } 3 \text { pm. Travel to the cemetery by a feeder service which takes } \\
8 \text { minutes for in-vehicle travel and } 15 \text { minutes for waiting and walking, and } \\
\text { requires paying a fare of } \$ 4 .\end{array}$ & $\square$ \\
\hline
\end{tabular}

\begin{tabular}{|l|l|c|}
\hline \multirow{5}{*}{ Game 4} & $\begin{array}{l}\text { Arrive during } 9 \text { to } 11 \mathrm{am} \text {. Travel to the cemetery by a feeder service which takes } \\
5 \text { minutes for in-vehicle travel and } 16 \text { minutes for waiting and walking, and } \\
\text { requires paying a fare of } \$ 5 .\end{array}$ & $\square$ \\
\cline { 2 - 3 } & $\begin{array}{l}\text { Arrive during } 11 \text { am to } 1 \mathrm{pm} \text {. Walk to the cemetery which takes } 40 \text { minutes for } \\
\text { waiting and walking (prohibited all vehicular access). }\end{array}$ & $\square$ \\
\cline { 2 - 3 } & $\begin{array}{l}\text { Arrive during } 1 \text { to } 3 \mathrm{pm} . \text { Walk to the cemetery which takes } 35 \text { minutes for } \\
\text { waiting and walking (prohibited all vehicular access). }\end{array}$ & $\square$ \\
\hline
\end{tabular}

\section{C) Family demographical characteristics}

C1. How many living apart families go grave-sweeping with you?

$\begin{array}{lllll}\square \text { None } & \square 1 & \square 2 & \square 3 & \square 4\end{array}$

C2. How many elderly family members (aged 65 or above) go grave-sweeping with you?
$\square$ None
$\square 1$
$\square 2$
$\square 3$ or above

C3. How many private vehicles does your family own?
$\square$ None
$\square 1$
$\square 2$
$\square 3$ or above

C4. How much does your family earn every month on average?
$\square \$ 10,000$ or below
$\square \$ 10,001-\$ 20,000$
$\square \$ 20,001-\$ 30,000$
$\square \$ 30,001-\$ 40,000$
$\square$ Above $\$ 40,000$ 